\title{
POTENTIAL HABITAT MODELING OF WATER HYACINTH IN LAKES OF NEPAL USING MAXENT ALGORITHM
}

\author{
S. S. Thakuri ${ }^{1, *}$, P. Shrestha ${ }^{1}$, M. Deuba ${ }^{1}$, P. Shah ${ }^{1}$, O. P. Bhandari ${ }^{1}$, S. Shrestha ${ }^{2}$
}

\begin{abstract}
${ }^{1}$ Department of Geomatics Engineering, Kathmandu University, Dhulikhel, Nepal - sumanthakuri246@gmail.com, alip.payal15@gmail.com,mohandeuba14@gmail.com, Pashupatimessi10@gmail.com,om.bhandari@ku.edu.np

${ }^{2}$ Photogrammetry and Remote Sensing Unit, Land Management Training Centre, Government of Nepal shr.sanjeevan@gmail.com
\end{abstract}

\section{Commission V, WG V/7 \& Commission IV, WG IV/6}

KEY WORDS: Maxent Algorithm, Representative Concentration Pathway, Invasive Alien Plant Species, Water Hyacinth

\begin{abstract}
:
Invasive Alien Plant Species are spreading outside of their natural geographic range. Water hyacinth (Eichhornia Crassipes) is one of the most widely and rapidly spreading invasive species throughout the tropical and subtropical regions of Nepal. In the last decade, water hyacinth has become a chronic problem in many major lakes of Nepal which have affected the habitat aquatic plants and animals. Our study focuses on potential habitat modeling of Water hyacinth over the major lakes of Nepal using Maxent algorithm. Primary data used for modeling were 19 bioclimatic variables and Shuttle Radar Topography Model (SRTM) Digital Elevation Model (DEM). After preparation of the species distribution model, major lakes of Nepal were overlaid over the model to prepare potential invasive map. The performance and accuracy of potential habitat distribution model was evaluated using parameter Area under the Receiver Operating Characteristic Curve (AUC) which was within the range of 0.9-1. Validation of the model was done for the year 2015 with precision and recall, overall accuracy and F-measure and its values are $93 \%$ and $85 \%, 87 \%$ and $89 \%$ respectively. The model prepared for 2030 and 2050 shows the most suitable habitat for water hyacinth is in province 2 of Nepal and the moderately suitable habitat for this species is plain area of Province 4, 7 and 5. Similarly, the area of potential habitat has been increasing from current scenario to 2030 and 2050 . From the potential invasion map, it can be observed that lakes in the Terai and Churey regions have the high risk of invasion of water hyacinth.
\end{abstract}

\section{INTRODUCTION}

Nepal's biodiversity is a reflection of its unique geographic position, diverse climatic condition and the widest altitudinal variations where many species from anywhere of the world may find the suitable habitat and climatic condition in Nepal. An assessment was undertaken by IUCN Nepal during 2002-2003 about the invasive alien plant species (IAPS) and it has reported that that are at least 219 invasive alien plant species (Shrestha, 2016). Among them Eichhornia crassipes (water hyacinth) is the worst aquatic invasive plant species.

Water hyacinth (Eichhornia Crassipes) is an erect, free-floating, stoloniferous, perennial herb. It grows to $1 \mathrm{~m}$ in height with buoyant leaves, which vary in size according to growth conditions. Water hyacinth is originally from South America and one of the world's most prevalent invasive aquatic plants. Water hyacinth has invaded freshwater systems in over 50 countries on five continents. The vegetative propagation of water hyacinth is very rapid such that the two plants of water hyacinth could multiply to 120,000 in 120 days, while thirty offspring could be produced from two parent plants within 23 days (Verma, Singh, Ganesha Raj, 2003). If uncontrolled, it eventually blankets the water surface killing and displacing other aquatic plants and animals and creating a visually unappealing landscape. The presence of this alien invasive plant species may alter the aquatic habitat structure, by creating a homogeneous habitat, thereby negatively affecting biological communities (Thamaga, Dube, 2018).

Many environmental factors such as temperature, precipitation, soil and surface humidity plays an important role for the distribution of this species. Similarly, the change in climate has affected the growth and reproduction of plant and has become one of the dominating variables for determining the geographical distribution of plant species (Wei et al., 2018). So, the models predicting the potential geographical distribution of species are important for determining the invasion of species based on different climatic scenarios. Species distribution models (SDMs) are scientifically proven tools for assessing and predicting the impacts of climate change on flora and fauna. SDMs dealing with presence-only data might be more advantageous over presence/absence modeling methods, conditional to the suitability for the study such as Maxent (Phillips, Dudík, 2008). Maxent is a general approach for presence only modeling of species distributions, suitable for all existing applications involving presence-only datasets (Dube et al., 2015). This approach estimates the most uniform distribution (maximum entropy) of sampling points compared to background locations given the constraints derived from the data. The presence only data are good enough for species distribution modeling and the 
AUC scores obtained for predictions can be sufficiently accurate (Elith et al., 2006).

Over the last few decades, a lot of studies have been carried out species, quantifying economic and ecological impacts(Thapa et al., 2018). The studies were focused only on terrestrial invasive plant species and its future prediction has not been practiced yet(Baidar et al., 2017). So, the major objectives of this study were i) to prepare the potential habitat modeling of water hyacinth in the lakes of Nepal in current and future scenario (2030 and 2050s) using Maxent algorithm; ii) to validate the potential habitat site of water hyacinth with current map using statistical measures; iii) to determine the important environment variables for the potential habitat of water hyacinth.

\section{STUDY AREA}

Nepal is a landlocked country located in South Asia with China in the north and India in the south, east and west. The country occupies 147,181 sq. $\mathrm{km}$ of land and lies in latitude from 26.4831 to 29.84121 and longitude from 80.33333 to 88.09436 . Nepal has been one of the appropriate habitats for many invasive species. There is high concentration of IAPS on the southern half of the country (which includes Terai, Siwalik and Mid Hills running east-west) with tropical to subtropical climate (Shrestha, 2016). Growth of Water hyacinth has become one of the major problems over major lakes of Nepal and other fresh water bodies. In the last decade, water hyacinth has become a chronic problem in many major lakes of Nepal such as Phewa Lake, Khaste Lake, Ghodaghodi Lake, Bis hazari Lake, etc. Figure 1 shows the study area along with major lakes of Nepal.

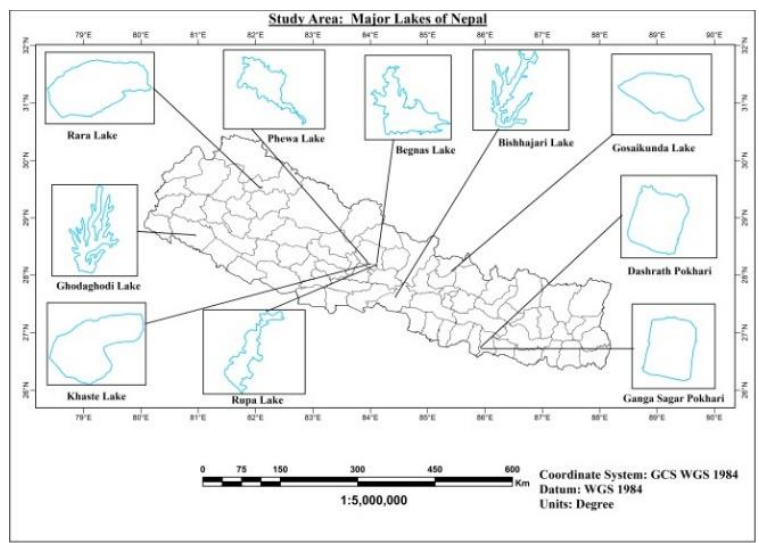

Figure 1. Study Area: Major Lakes of Nepal

\section{METHODOLOGY}

\subsection{Data Collection}

The location information about the occurrence of water hyacinth was obtained from Google Earth platform. 146 sample points from different lakes and ponds were collected all over Nepal and the records were imported into Microsoft Excel and saved as ".CSV" format.

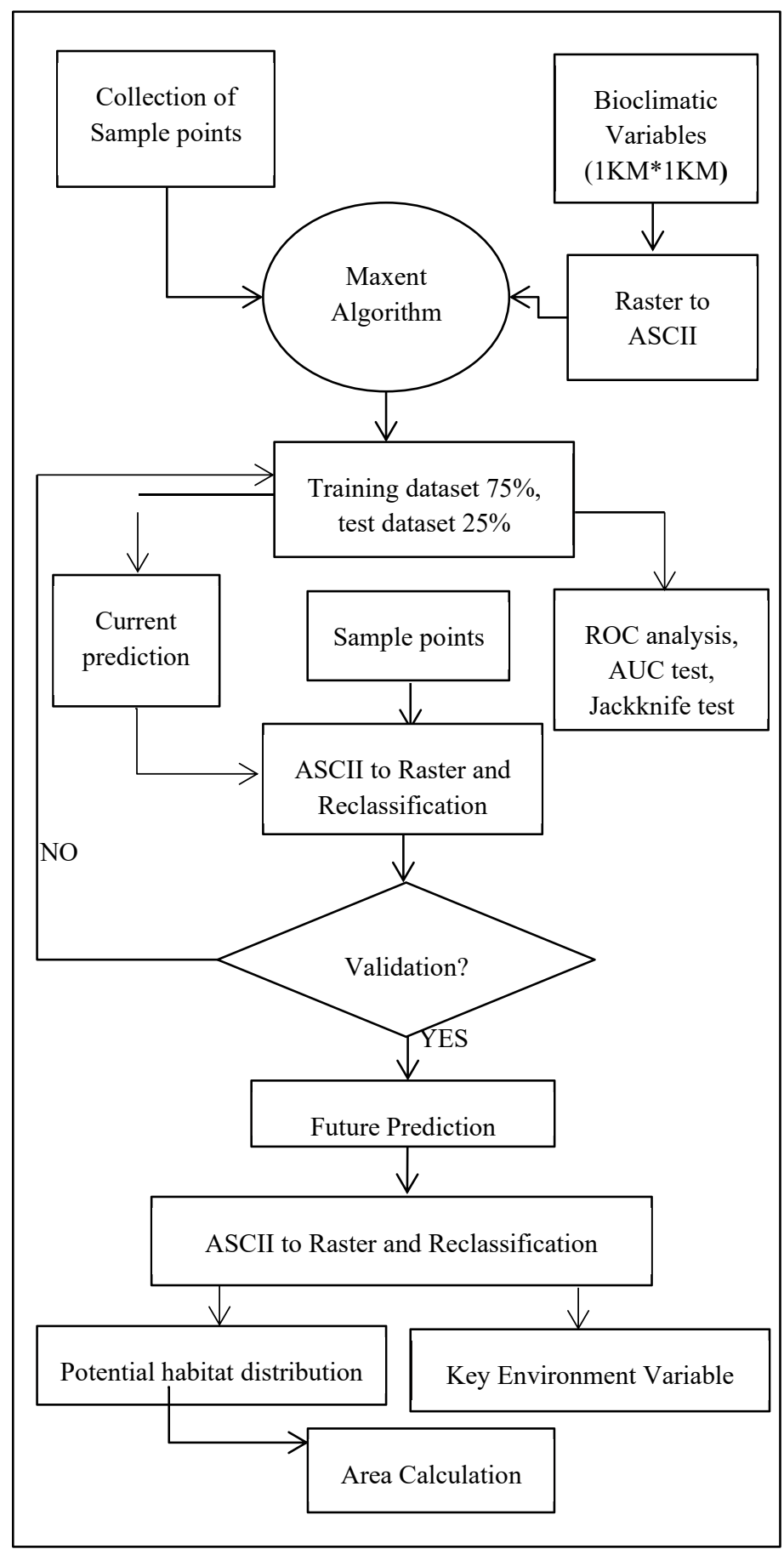

Figure 2. Methodological Flowchart of Potential Habitat Distribution of water hyacinth.

We selected 19 bioclimatic variables from website (https://www.worldclim.org/bioclim) that may influence the distribution of water hyacinth. These bioclimatic variables have $30 \mathrm{~s}(1 \mathrm{~km})$ spatial resolution obtained from the world climate database for current year. Moreover, elevation is also major factor that affects the growth of water hyacinth. So, ASTER DEM of resolution 30 meter was downloaded from the website (https://search.earthdata.nasa.gov). Further the DEM was 
resampled to the resolution of $1 \mathrm{~km}$. Figure 2 shows the overall workflow of this study.

To determine the future distribution of the water hyacinth under different climate trajectories, we used datasets of future climate from the Climate Change, Agriculture and Food Security (CCAFS) website (www.ccafs-climate.org). Representative Concentration Pathways (RCPs) (including RCP2.6, RCP4.5, RCP6.0 and RCP8.5) are four greenhouse gas concentration trajectories adopted by the Intergovernmental Panel on Climate Change (IPCC) in its Fifth Assessment Report (AR5). These pathways are used in climate modeling and research to describe four possible future climates, all of which are considered possible depending on how many greenhouse gases are emitted in the near future. However we selected RCP2.6 (the minimum greenhouse gas emission scenario) and RCP8.5 (the maximum greenhouse gas emission scenario to model the potential habitat of water hyacinth in 2030 and 2050. All environmental data used in this model had a 30 second spatial resolution (also referred to as $1 \mathrm{~km}$ spatial resolution).

\subsection{Current Habitat Distribution Modeling}

Maximum entropy model (Maxent version 3.3.3) was used for the preparation of potential distribution model. This is wellsuited distribution model for different species as it is easy to use as it works with presence only dataset. So, the sample points for this model where the species actually exist. For each species, $75 \%$ of the location point data were used as a training model, and the remaining $25 \%$ for validating the Maxent model(Zhang et al., 2018). The output of the Maxent was in ASCII format which was further transformed into raster format using the ArcMap tool in ArcGIS software for further analysis.

\subsection{Determination of the key variables}

After executing Maxent model for modeling current distribution Water hyacinth using 19 bioclimatic variables and SRTM DEM, the model resulted percentage contribution of each environmental variable for preparation of current distribution model. The variables which have contribution more than $0 \%$ were selected as key variables.

\subsection{Validation}

After preparing the current habitat distribution model, it is necessary to check the quality and accuracy of the model. For validation purpose, we prepared key bioclimatic variables of 2015 using precipitation data from CHIRP and land surface temperature (LST) from MODIS satellite imageries. Using these variables, potential habitat distribution model of year 2015 was prepared. Then the sample points were generated in the lakes of Nepal using stratified sampling method and calculated the true positive, true negative, false positive and false negative value in the specific area. With these values, overall accuracy, precision, recall and F-measure were calculated.

\subsection{Future Potential Habitat Distribution Modeling}

After using the current climatic data to model the spatial extent of suitable habitat for Water hyacinth, modeling projections were performed for four future climate scenarios (RCP2.6-2030,
RCP2.6-2050, RCP8.5-2030, and RCP8.5-2050) to predict the extent of suitable habitat for the species in the future.

For evaluation of our output, several statistical analysis and tests were done. The robustness of evaluation for the Maxent model, threshold-independent receiver-operating characteristic (ROC) analyses was used. An area under the receiver-operating characteristic curve (AUC) was examined for additional precision analyses. The Jackknife test was used to assess the relative importance of the variables.

\subsection{Area Calculation}

The selected lakes were overlaid in the current and future habitat prediction model. Since the area covered by lakes was smaller than $1 \mathrm{sq} . \mathrm{km}$, the raster model was resampled into $100 \mathrm{~m}$ and based on raster value of each pixel the habitat suitability area of each lake was determined.

\section{RESULT AND DISCUSSION}

\subsection{Potential habitat distribution model of current year and its accuracy}

Potential distribution of Water hyacinth for whole Nepal was done by using Maxent algorithm. Potential habitat distribution map was overlaid with provincial map of Nepal which would hel $\mathrm{p}$ to visualize potential habitat over different provinces in current year. The AUC training values were 0.973 and 0.96 for training and test sample points respectively, indicating the model performed well and generated excellent evaluation(Swets, 1988). Similarly, to validate the potential distribution model, the Maxent model was run for the year 2015. The sample points collected from Google Earth and environmental variables for the year 2015 were used to run the Maxent model. Figure 3 shows the potential habitat distribution model of current year in major lakes of Nepal and Figure 4 shows the potential habitat distribution model of 2015. Table 1 shows the shows precision and recall, overall accuracy and F-measures whose values are adequate as per the requirement of our study.

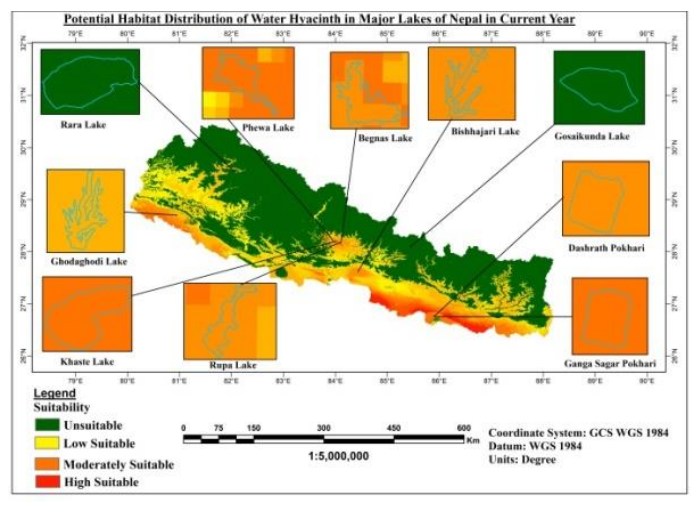

Figure 3. Potential Habitat Distribution of Water Hyacinth in the Lakes in current year 


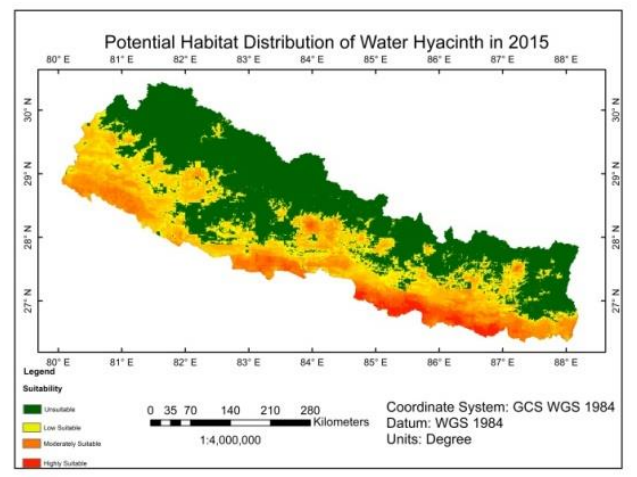

Figure 4. Potential Habitat Distribution of Water Hyacinth in 2015

Table 1. Accuracy Assessment of current distribution model

\begin{tabular}{|c|c|}
\hline Accuracy Metrics & Value \\
\hline Overall Accuracy & $87 \%$ \\
\hline Precision & $93 \%$ \\
\hline Recall & $85 \%$ \\
\hline F-measure & $89 \%$ \\
\hline
\end{tabular}

\subsection{Key Environment Variables}

Using the Maxent model, the key variables that influence the potential invasion of water hyacinth were determined through the percent contribution values. Two variables digital elevation model and bio1 i.e., Annual mean temperature were identified as the variables conditions that contribute the most to water hyacinth's potential distribution. Similarly, to get alternative estimates of which variables are most important in the model, a jackknife test was also run. The environmental variable with highest gain when used in isolation is Digital elevation model, which therefore appears to have the most useful information by itself. The environmental variable that decreases the gain the most when it is omitted is bio14 i.e. Precipitation of driest month, which therefore appears to have the most information that isn't present in the other variables. Table 2 shows the key variables that influence the invasion of water hyacinth are tabulated below along with its percentage contribution in current scenario. Figure 5 shows the jackknife test of different environmental variables.

Table 2. Key Variables along with its percent contribution

\begin{tabular}{|c|c|}
\hline Environment Variables & $\begin{array}{c}\text { Percent } \\
\text { Contribution }\end{array}$ \\
\hline
\end{tabular}

\begin{tabular}{|c|c|}
\hline $\begin{array}{c}\text { Annual Mean Temperature } \\
\text { (BIO1) }\end{array}$ & 10.4 \\
\hline $\begin{array}{c}\text { Min Temperature of Coldest } \\
\text { Month (BIO6) }\end{array}$ & 7.4 \\
\hline $\begin{array}{c}\text { Temperature Annual } \\
\text { Range(BIO7) }\end{array}$ & 2.1 \\
\hline $\begin{array}{c}\text { Mean Temperature of Wettest } \\
\text { Quarter (BIO8) }\end{array}$ & 0.7 \\
\hline $\begin{array}{c}\text { Mean Temperature of Warmest } \\
\text { Quarter (BIO10) }\end{array}$ & 2.7 \\
\hline $\begin{array}{c}\text { Annual Precipitation (BIO12) } \\
\text { Precipitation of Driest Month } \\
\text { (BIO14) }\end{array}$ & 2.4 \\
\hline $\begin{array}{c}\text { Precipitation of Warmest } \\
\text { Month (BIO18) }\end{array}$ & 6.5 \\
\hline $\begin{array}{c}\text { SRTM DEM } \\
\text { (B) }\end{array}$ & 3.2 \\
\hline
\end{tabular}

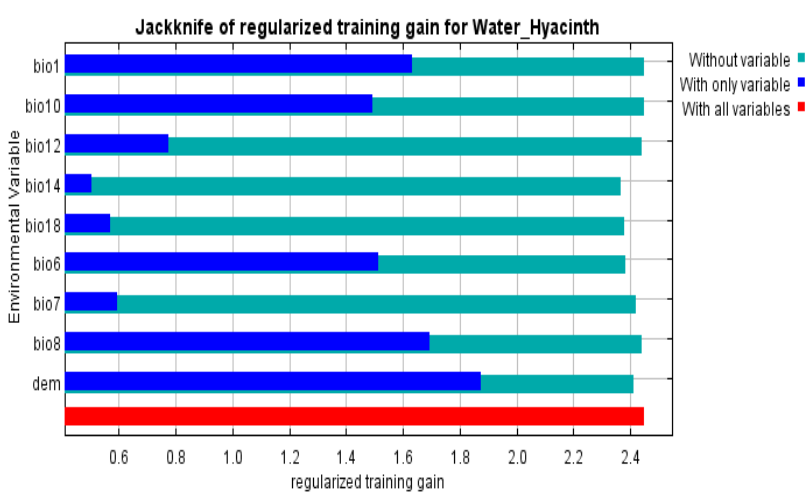

Figure 5. Jackknife of regularized training gain for Water Hyacinth

Therefore, from both of the above analysis, three variables digital elevation model, precipitation of driest month and annual mean temperature have more contribution for predicting the potential invasion of water hyacinth.

\subsection{Potential Habitat Distribution in year 2030 and 2050 A.D.}

From the important key variables, the potential habitat distribution model for year 2030 and 2050 was prepared. Selected bioclimatic variables were defined by two Representative Concentration Pathway; they were RCP 2.6 and RCP 8.5 as these pathways defines extremities of emission scenarios of greenhouse gases over time. Using these bioclimatic variables along with SRTM DEM was used and following 
potential distribution maps were prepared. Figure 6 and 7 show the potential habitat distribution under RCP 2.6 and RCP 8.5.

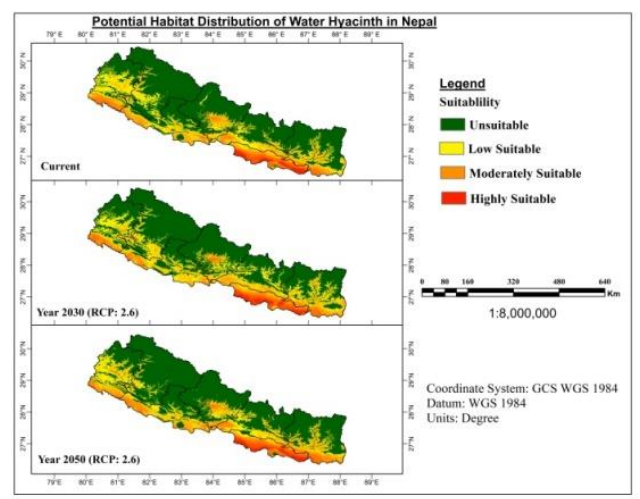

Figure 6. Potential Habitat Distribution under RCP 2.6

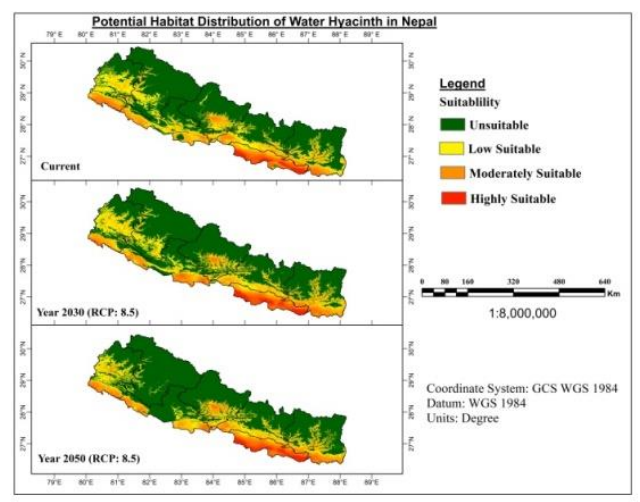

Figure 7. Potential Habitat Distribution under RCP 8.5

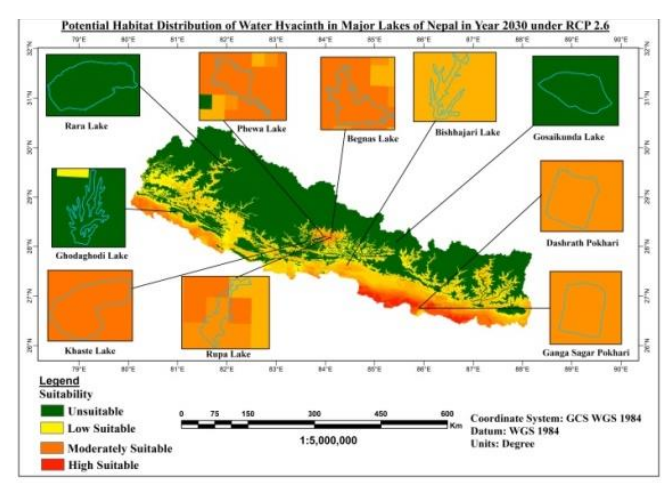

Figure 8. Potential Habitat Distribution of Water Hyacinth in the lakes of Nepal in year 2030 under RCP 2.6

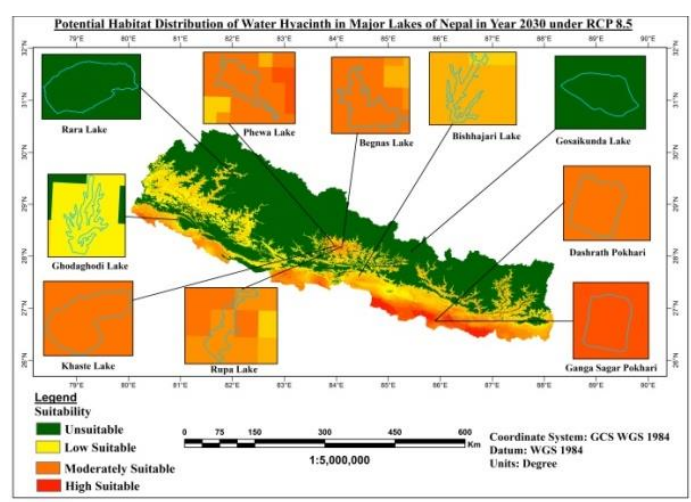

Figure 9. Potential Habitat Distribution of Water Hyacinth in Major lakes of Nepal in year 2030 under RCP 8.5

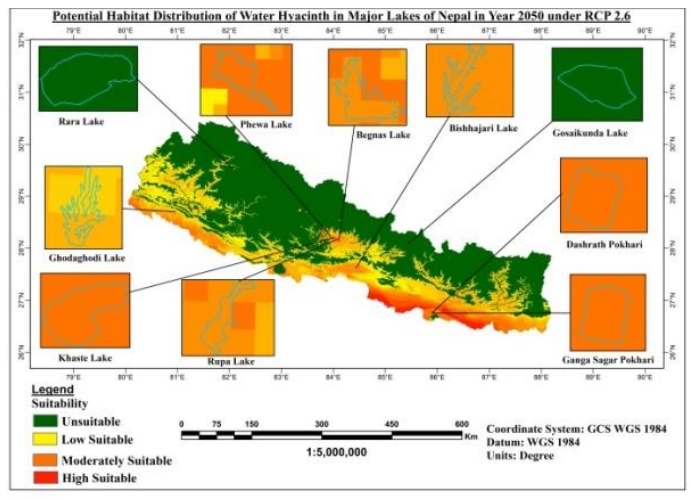

Figure 10. Potential Habitat Distribution of Water Hyacinth in the lakes of Nepal in year 2050 under RCP 2.6

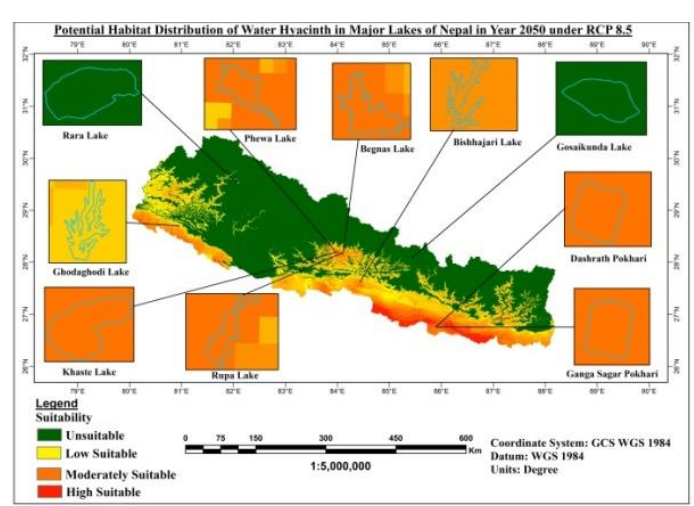

Figure 11. Potential Habitat Distribution of Water Hyacinth in the lakes of Nepal in year 2050 under RCP 8.5 
The model performance of future potential model distribution was analyzed based on its AUC value. The AUC value for both year 2030 and 2050 is in between 0.9-1 which shows that the model performs excellent and generate excellent evaluation (Baldwin, 2009). Table 3 shows the AUC value for year 2030 and 2050 under RCP 2.6 and 8.5 respectively.

Table 3. AUC value for year 2030 and 2050

\begin{tabular}{|c|c|c|c|c|c|c|c|c|}
\hline $\begin{array}{c}\text { Scenari } \\
\text { o }\end{array}$ & \multicolumn{3}{|c|}{ Year 2030 } & \multicolumn{3}{c|}{ Year 2050 } \\
\cline { 2 - 8 } & \multicolumn{2}{|c|}{ RCP2.6 } & \multicolumn{2}{|c|}{ RCP8.5 } & \multicolumn{2}{c|}{ RCP2.6 } & \multicolumn{2}{c|}{ RCP8.5 } \\
\cline { 2 - 8 } & $\begin{array}{c}\text { Trai } \\
\text { ning }\end{array}$ & $\begin{array}{c}\text { Te } \\
\text { st }\end{array}$ & $\begin{array}{c}\text { Trai } \\
\text { ning }\end{array}$ & $\begin{array}{c}\text { Tes } \\
\text { t }\end{array}$ & $\begin{array}{c}\text { Trai } \\
\text { ning }\end{array}$ & $\begin{array}{c}\text { Te } \\
\text { st }\end{array}$ & $\begin{array}{c}\text { Trai } \\
\text { ning }\end{array}$ & $\begin{array}{c}\text { Te } \\
\text { st }\end{array}$ \\
\hline $\begin{array}{c}\text { AUC } \\
\text { Value }\end{array}$ & 0.97 & 0. & 0.971 & 0.9 & 0.97 & $\begin{array}{c}0 . \\
94\end{array}$ & 0.971 & 0.9 \\
52
\end{tabular}

The potential distribution maps were categorized into four categories based on suitability; highly suitable $(>60 \%)$, moderately suitable $(60 \%-40 \%)$, Low suitable $(40 \%-20 \%)$ and unsuitable $(<20 \%)$ (Zhang et al., 2018). Table 4 and 5 shows the potential habitat area of water hyacinth in the major lakes of Nepal in current and future scenario under RCP 2.6 and 8.5.
Table 4. Potential Area of Water Hyacinth in the lakes in current and future scenarios under RCP2.6.

\begin{tabular}{|c|c|c|c|c|c|c|c|c|c|c|c|c|}
\hline & & 吾 & $\begin{array}{l}\text { n̊? } \\
\stackrel{0}{0}\end{array}$ & 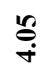 & $\underset{\ddot{\rho}}{\tilde{\rho}}$ & 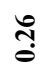 & $\frac{\mathscr{1}}{3}$ & 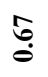 & $\stackrel{7}{0}$ & $\stackrel{\Upsilon}{-}$ & $\stackrel{ \pm}{\stackrel{D}{0}}$ & $\stackrel{ \pm}{\stackrel{\Delta}{0}}$ \\
\hline & & 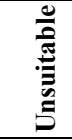 & $\begin{array}{l}0 \\
\stackrel{n}{0} \\
0\end{array}$ & 1 & 1 & 1 & 1 & 1 & 1 & 1 & 1 & \\
\hline & & 范 & 1 & 1 & 1 & 1 & $\stackrel{\mathfrak{a}}{\stackrel{0}{0}}$ & ?? & 1 & 1 & 1 & \\
\hline & नें & 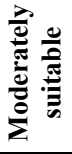 & 1 & $\begin{array}{l}n \\
\dot{f}\end{array}$ & $\underset{\text { Ș }}{\tilde{r}}$ & ָ̊ & 1 & $\hat{n}$ & $\stackrel{1}{3}$ & $\stackrel{\text { Iִ }}{\longrightarrow}$ & $\stackrel{t}{0}$ & c \\
\hline & & 尝: & 1 & 1 & 1 & I & 1 & 1 & 1 & 1 & 1 & \\
\hline \multirow{9}{*}{ 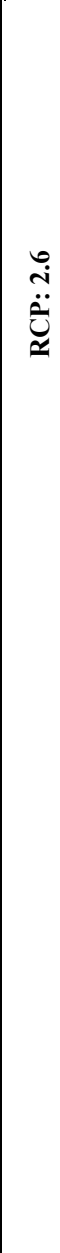 } & & 总 & $\begin{array}{l}0 \\
\stackrel{0}{0} \\
0\end{array}$ & 1 & 1 & 1 & $\stackrel{\mathfrak{a}}{\stackrel{2}{0}}$ & $\stackrel{5}{0}$ & I & 1 & 1 & \\
\hline & 8 & 芺 & I & 1 & 1 & ก̊ & 1 & 1 & 1 & $\begin{array}{l}0 \\
\stackrel{0}{0}\end{array}$ & 1 & \\
\hline & $\stackrel{\sim}{\sim}$ & 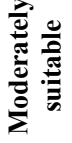 & 1 & $\begin{array}{l}2 \\
\dot{f} \\
\dot{\gamma}\end{array}$ & $\underset{\text { d̦ }}{\text { r. }}$ & 1 & 1 & 1 & $\frac{1}{0}$ & $\stackrel{\circ}{\circ}$ & $\stackrel{t}{0}$ & ¿t. \\
\hline & & 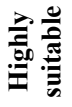 & 1 & 1 & 1 & 1 & 1 & 1 & 1 & 1 & 1 & \\
\hline & & 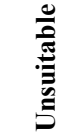 & $\begin{array}{l}0 \\
\stackrel{0}{0} \\
0\end{array}$ & 1 & 1 & 1 & $\stackrel{a}{\stackrel{2}{0}}$ & 1 & 1 & 1 & 1 & \\
\hline & $\ddot{z}$ & 党 & 1 & 1 & $\begin{array}{l}\tilde{v} \\
\stackrel{N}{N}\end{array}$ & I & 1 & $\stackrel{\sigma}{0}$ & 1 & 1 & 1 & \\
\hline & $\Xi$ & 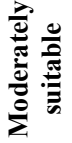 & I & $\begin{array}{l}\stackrel{2}{o} \\
\dot{\gamma}\end{array}$ & $\overbrace{0}^{+}$ & ָ̊ & 1 & I & $\stackrel{2}{\circ}$ & $\stackrel{\sim}{\longrightarrow}$ & $\stackrel{+}{0}$ & ț \\
\hline & & 光: & 1 & 1 & 1 & 1 & 1 & 1 & 1 & 1 & 1 & \\
\hline & & 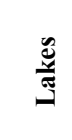 & $\begin{array}{c}\widetilde{\pi} \\
\widetilde{\sim}\end{array}$ & $\frac{\tilde{z}}{\frac{\pi}{2}}$ & 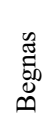 & 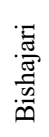 & 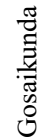 & 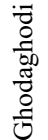 & 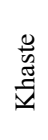 & 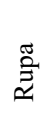 & 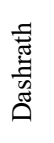 & 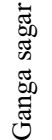 \\
\hline
\end{tabular}


Table 5. Potential Area of water hyacinth in the lakes in current and future scenario under RCP8.5.

\begin{tabular}{|c|c|c|c|c|c|c|c|c|c|c|c|c|}
\hline & & 苞 & $\begin{array}{l}\stackrel{0}{0} \\
\stackrel{\theta}{0}\end{array}$ & $\stackrel{\mathscr{C}}{\dot{\theta}}$ & $\underset{\dot{\rho}}{\tilde{d}}$ & $\stackrel{\text { İ }}{8}$ & $\stackrel{\mathscr{2}}{\dddot{3}}$ & $\stackrel{\widehat{b}}{\dot{0}}$ & $\frac{\mathfrak{T}}{0}$ & $\stackrel{\Upsilon}{\nearrow}$ & $\stackrel{\Xi}{\stackrel{\Xi}{\theta}}$ & $\stackrel{\vec{\theta}}{\stackrel{\Delta}{0}}$ \\
\hline & & 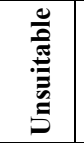 & $\begin{array}{l}\stackrel{0}{?} \\
\stackrel{0}{n}\end{array}$ & 1 & 1 & 1 & 1 & 1 & 1 & 1 & 1 & 1 \\
\hline & & 童竞: & 1 & 1 & 1 & 1 & $\stackrel{2}{\stackrel{2}{0}}$ & $\stackrel{0}{0}$ & 1 & 1 & 1 & 1 \\
\hline & సิ & 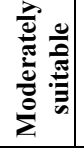 & 1 & $\begin{array}{l}\mathscr{2} \\
\dot{+}\end{array}$ & $\stackrel{\tilde{\sigma}}{\tilde{r}}$ & $\stackrel{\text { N̊}}{0}$ & 1 & 1 & $\frac{1}{0}$ & $\stackrel{\text { I }}{\sim}$ & $\stackrel{t}{0}$ & $\stackrel{t}{0}$ \\
\hline & & 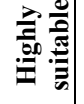 & 1 & 1 & 1 & 1 & 1 & 1 & 1 & 1 & 1 & 1 \\
\hline & & 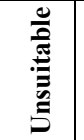 & $\begin{array}{l}0 \\
\stackrel{n}{0} \\
n\end{array}$ & 1 & 1 & 1 & $\stackrel{2}{\stackrel{2}{0}}$ & $\stackrel{\hat{\sigma}}{0}$ & 1 & 1 & 1 & 1 \\
\hline$\dddot{\infty}$ & ల్లి & 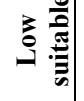 & I & 1 & 1 & $\stackrel{3}{0}$ & 1 & 1 & 1 & 1 & 1 & 1 \\
\hline 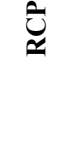 & సิ & 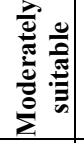 & 1 & $\begin{array}{l}\stackrel{2}{0} \\
\dot{+}\end{array}$ & 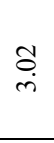 & ֶิ & 1 & 1 & $\stackrel{1}{3}$ & $\stackrel{\text { I }}{\sim}$ & $\stackrel{t}{0}$ & $\begin{array}{l} \pm \\
\stackrel{0}{0}\end{array}$ \\
\hline & & 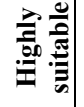 & 1 & 1 & 1 & 1 & 1 & 1 & 1 & 1 & 1 & 1 \\
\hline & & 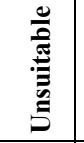 & $\begin{array}{l}\stackrel{2}{0} \\
\stackrel{0}{0}\end{array}$ & 1 & 1 & 1 & $\stackrel{a}{\stackrel{2}{0}}$ & 1 & 1 & 1 & 1 & 1 \\
\hline & 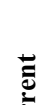 & 它产 & 1 & 1 & $\stackrel{\stackrel{\vec{n}}{i}}{\vec{j}}$ & 1 & 1 & $\stackrel{\hat{\sigma}}{0}$ & 1 & 1 & 1 & 1 \\
\hline & $\tilde{E}$ & 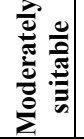 & 1 & $\begin{array}{l}n \\
\dot{o} \\
\dot{f}\end{array}$ & $\stackrel{\infty}{+}$ & ֻ̊? & 1 & 1 & $\stackrel{1}{\stackrel{0}{0}}$ & $\stackrel{\text { Iִ }}{\sim}$ & $\stackrel{+}{0}$ & $\stackrel{+}{0}$ \\
\hline & & 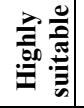 & 1 & 1 & I & 1 & 1 & 1 & 1 & 1 & 1 & 1 \\
\hline & & 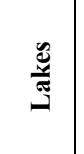 & $\stackrel{\widetilde{J}}{\approx}$ & $\frac{\pi}{2}$ & 节 & 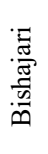 & 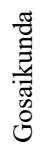 & 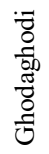 & 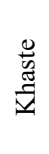 & 范 & 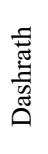 & 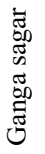 \\
\hline
\end{tabular}

The result shows that the major lakes of Nepal like Rupa Lake, Khaste lake, Phewa Lake and Begnas Lake which are situated in Province 4 have suitable habitat of water hyacinth and in the future scenarios these lakes have been shown as the major habitat of this species. Similarly, the water bodies which are situated in
Terai region such as Dashrath and Gangasagar has the major suitable habitat of water hyacinth in current and future scenario and the area covered by the species from RCP 2.6 to RCP 8.5 is increasing. This is because greenhouse gases emission under RCP 8.5 is more which results higher carbon contain in atmosphere and higher pollution contain in water bodies which enhance growth of water hyacinth.

From the potential invasion map, it can be observed that lakes in the Terai and churey areas have the high risk of invasion. The hilly and Himalayan areas of Nepal are colored in mostly green and somewhat blue indicating lower risk of invasion. It is because water hyacinth is strongly damaged by frost, and the growth rate is greatly reduced at temperatures below $10{ }^{\circ} \mathrm{C}$. This is reasonable with the sample points that we collected showed high level of presence of water hyacinth in plain areas that any other land cover. Plain areas are more affected because the weeds get the required temperature and moisture for its proper growth. Also the main reason behind its growth is water pollution; in these areas the pollution rate is very high which also influence its growth rate.

The potential invasion model prepared for current, 2030 and 2050 shows that major possibility of water hyacinth invasion in Rupa Lake, Begnas Lake, Phewa Lake, Khaste Lake which is situated in Province 4, Bis Hazari Lake in Province 3, Ghodaghodi Lake in Province 7 and Dasrat Pokhari and Ganga Sagar Pokhari in Province 2. The model prepared for 2030 and 2050 shows the most suitable habitat for water hyacinth is seen in province 2 of Nepal and the moderately suitable habitat for this weed is plain area of Province 4, 7and 5. Similarly, the area of potential habitat has been increasing from current scenario to 2030 and 2050. So, in the future scenarios the invasion rate of water hyacinth is very high which might pose a threat to the native ecosystems in Nepal.

\section{CONCLUSION}

This study indicates that the habitat distribution pattern of water hyacinth could be modeled through Maxent using its occurrence records and 9 environmental factors in current and future scenario. The result shows that the highly suitable habitat of water hyacinth has been increased under future climate change scenarios in (RCP2.6 and RCP8.5) in 2030s and (RCP2.6 and RCP8.5) in 2050s. The Terai and Churey range of Nepal have the highest invasion rate and the lakes within this area have been shown as the highly suitable habitat of water hyacinth.

Other environmental factors like are sunlight radiation, water contamination and wind speed that are need to be considered for predicting the suitable habitat of water hyacinth. So, incorporating these environmental factors on predicting the suitable habitat of water hyacinth is highly recommended for better analysis.

\section{REFERENCES}

Baidar, T., Shrestha, A. B., Ranjit, R., Adhikari, R., Ghimire, S., \& Shrestha, N., 2017. Impact assessment of mikania micrantha on land cover and maxent modeling to predict its potential 
invasion sites. International Archives of the Photogrammetry, Remote Sensing and Spatial Information Sciences - ISPRS Archives 42(1W1), 305-310

Baldwin, R. A., 2009. Use of Maximum Entropy Modeling in Wildlife Research. Entropy, 854-866.

Dube, T., Mutanga, O., Seutloali, K., Adelabu, S., \& Shoko, C., 2015. Water quality monitoring in sub-Saharan African lakes: a review of remote sensing applications. African Journal of Aquatic Science 40(1), 1-7

Elith, J., H. Graham, C., P. Anderson, R., Dudík, M., Ferrier, S., Guisan, A., E. Zimmermann, N., 2006. Novel methods improve prediction of species' distributions from occurrence data. Ecography 29(2), 129-151

Lamsal, P., Kumar, L., Aryal, A., \& Atreya, K., 2018. Invasive alien plant species dynamics in the Himalayan region under climate change. Ambio 47(6), 697-710

Phillips, S. J., \& Dudík, M., 2008. Modeling of species distributions with Maxent: New extensions and a comprehensive evaluation. Ecography 31(2), 161-175

Shrestha, B. B., 2016. Invasive Alien Plant Species (IAPS) in Nepal. Frontiers of Botany, 269-284 .

Swets, J. A., 1988. Measuring the accuracy of diagnostic systems. Science Science 240(4857), 1285-1293

Thamaga, K. H., \& Dube, T., 2018. Remote sensing of invasive water hyacinth (Eichhornia crassipes): A review on applications and challenges. Remote Sensing Applications: Society and Environment

Thapa, S., Chitale, V., Rijal, S. J., Bisht, N., \& Shrestha, B. B., 2018. Understanding the dynamics in distribution of invasive alien plant species under predicted climate change in Western Himalaya. PLoS ONE 13(4), 1-16

Verma, R., Singh, S. P., \& Ganesha Raj, K., 2003. Assessment of changes in water-hyacinth coverage of water bodies in northern part of Bangalore city using temporal remote sensing data. Current Science 84(6), 795-804

Wei, B., Wang, R., Hou, K., Wang, X., \& Wu, W., 2018. Predicting the current and future cultivation regions of Carthamus tinctorius L. using MaxEnt model under climate change in China. Global Ecology and Conservation 16, 1-12
Yang, X. Q., Kushwaha, S. P. S., Saran, S., Xu, J., \& Roy, P. S., 2013. Maxent modeling for predicting the potential distribution of medicinal plant, Justicia adhatoda L. in Lesser Himalayan foothills. Ecological Engineering 51, 83-87

Zhang, K., Yao, L., Meng, J., \& Tao, J., 2018. Maxent modeling for predicting the potential geographical distribution of two peony species under climate change. Science of the Total Environment 634, 1326-1334 